\title{
Characteristics of dynamic processing in the visual field of patients with age-related maculopathy
}

\author{
Werner Eisenbarth • Manfred MacKeben • \\ Dorothe A. Poggel • Hans Strasburger
}

Received: 7 December 2006 /Revised: 28 April 2007 / Accepted: 7 May 2007 / Published online: 19 September 2007

(C) Springer-Verlag 2007

\begin{abstract}
Purpose To investigate the characteristics of dynamic processing in the visual field of patients with age-related maculopathy (ARM) by measuring motion sensitivity, double-pulse resolution (DPR), and critical flicker fusion. Methods Fourteen subjects with ARM (18 eyes), 14 agematched controls (19 eyes), and 7 young controls (8 eyes) served as subjects. Motion contrast thresholds were
\end{abstract}

Presented at ARVO 2004 (\#3084): Reduced motion sensitivity inside and outside the macula in age-related maculopathy.

W. Eisenbarth · D. A. Poggel $\cdot$ H. Strasburger

Generation Research Program (GRP), Human Science Center,

Ludwig-Maximilians University,

Munich, Germany

W. Eisenbarth

Academy of Applied Optometry (FFA),

Marsplatz 8,

80335 Munich, Germany

email: eisenbarth@ffa-muenchen.de

\section{MacKeben}

The Smith-Kettlewell Eye Research Institute,

San Francisco, CA, USA

e-mail: mm@ski.com

\section{A. Poggel}

Center for Innovative Visual Rehabilitation,

Boston VA Medical Center,

Boston, MA, USA

email: dapoggel@bu.edu

H. Strasburger $(\bowtie)$

Department of Medical Psychology, University of Göttingen,

Göttingen, Germany

e-mail: strasburger@med.uni-goettingen.de determined by a four-alternative forced-choice (4 afc) staircase procedure with a modification by Kernbach for presenting a plaid $\left(\right.$ size $\left.=3.8^{\circ}\right)$ moving within a stationary spatial and temporal Gaussian envelope in one of four directions. Measurements were performed on the horizontal meridian at $10^{\circ}, 20^{\circ}, 30^{\circ}, 40^{\circ}$, and $60^{\circ}$ eccentricity. DPR was defined as the minimal temporal gap detectable by the subject using a 9-fold interleaved adaptive procedure, with stimuli positioned on concentric rings at $5^{\circ}, 10^{\circ}$, and $20^{\circ}$ eccentricity on the principal and oblique meridians. Critical flicker fusion thresholds (CFF) and the Lanthony D-15 color vision test were applied foveally, and the subjects were free to use their fovea or whatever retinal area they needed to use instead, due to their retinal lesions caused by ARM. All measurements were performed under photopic conditions.

Results Motion contrast sensitivity in subjects with ARM was pronouncedly reduced $(0.23-0.66 \log$ units, $p<0.01)$, not only in the macula but in a region up to $20^{\circ}$ eccentricity. In the two control groups, motion contrast sensitivity systematically declined with retinal eccentricity (0.009-0.032 log units/ degree) and with age (0.01 log units/year). Double-pulse thresholds in healthy subjects were approximately constant in the central visual field and increased outside a radius of $10^{\circ}$ $(1.73 \mathrm{~ms} /$ degree $)$. DPR thresholds were elevated in subjects with ARM (by $23-32 \mathrm{~ms}, p<0.01$ ) up to $20^{\circ}$ eccentricity, and their foveal CFFs were increased by $5.5 \mathrm{~Hz}$ or $14 \%(p<0.01)$ as compared with age-matched controls.

Conclusions Dynamic processing properties in subjects with ARM are severely impaired in the central visual field up to $20^{\circ}$ eccentricity, which is clearly beyond the borders of the macula.

Keywords ARM - Contrast sensitivity - Motion perception . Temporal resolution $\cdot$ Visual field 


\section{Introduction}

Age-related maculopathy (ARM) is the most common cause of loss of central vision in industrialized countries $[17,26,30,33,34,62]$. Almost all clinical assessments of the consequences of ARM for basic visual functions and quality of life refer to foveal or macular vision. However, a few studies have shown that retinal defects can occur beyond $10^{\circ}$ eccentricity, which can be considered the maximum radial extent of the macula. Sunness et al., for instance, described histopathological anomalies outside the central retina, whereas sensitivity was unchanged in traditional static perimetry [55].

Curcio et al. described that, beyond general age-related photoreceptor loss, five out of six ARM-affected donor eyes showed cone and rod loss in parafoveal regions [12]. The latter can be expected to reduce dark adaptation performance, which was confirmed up to $25^{\circ}$ eccentricity by Brown et al. [9]. In addition, ARM affects temporal aspects of visual information processing. Mayer et al. found reduced temporal resolution of ARM patients as measured by foveal flicker sensitivity with a stimulus of $2.8^{\circ}$ diameter [40, 41]. Brown and Lovie-Kitchin showed reduced flicker resolution in the fovea and at $10^{\circ}$ and $20^{\circ}$ eccentricity and concluded that "the functional effects of ARM are not confined to the central retina, but affect a large region of the visual field" [11]. Falsini et al. found cone-mediated flicker sensitivity (CFS) losses in ARM by evaluating the focal electroretinogram (FERG) as a function of flicker modulation depth in the macula ( $9^{\circ}$ radius) [13].

In summary, the results of these studies show age-related as well as ARM-related functional loss of dynamic processing. However, whether the loss is confined to the macula has not been definitively answered. A further question is whether a loss outside the macula is specific to temporal resolution or whether other temporal aspects of retinal processing, such as motion sensitivity, can also be affected beyond the macula in patients suffering from ARM. Furthermore, we asked whether the impairment is confined to the magnocellular system or also involves the parvocellular pathway.

\section{Methods}

Motion contrast threshold

\section{Experimental setup}

The experimental setup allowed measurements of peripheral motion perception up to $60^{\circ}$ eccentricity under photopic conditions (luminance $=75 \mathrm{~cd} / \mathrm{m}^{2}$ ). It consisted of a white, semicircular $\left(180^{\circ}\right)$ plastic screen (radius $90 \mathrm{~cm}$, height
$60 \mathrm{~cm}$ ) with a rectangular opening in the center. A flatscreen LCD display was mounted behind the opening for the presentation of the test patterns. The subjects sat in front of the screen at a distance of $90 \mathrm{~cm}$ and monocularly fixated one of the fixation marks in primary view (fixation crosses with diameter $=4 \mathrm{~cm}$ and bar width $=0.5 \mathrm{~cm})$. The marks were attached to the plastic background at $10^{\circ}, 20^{\circ}$, $30^{\circ}, 40^{\circ}$, and $60^{\circ}$ eccentricity (Fig. 1). Fixation was monitored by a mirror mounted below the LCD display. Thus, the examiner could monitor the subject's eye movements during the presentation of a stimulus. Additionally, the mirror could be moved horizontally to allow a clear view of the patient's eye, even in extremely peripheral positions. We are confident that the examiner was able to detect saccadic eye movements of at least $5^{\circ}$ amplitude, which is still only half of the distance between two measuring locations.

\section{Monitor calibration}

To achieve specified stimulus luminance and contrast, the monitor's gamma curve (screen luminance vs. gray value) needs to be taken into account during stimulus presentation [4, $51,52,54]$. We measured this for our monitor using Irtel's PXL software to set the screen uniformly at the 256 possible gray levels and measured center screen luminance with a digital luminance meter (Gossen Mavomonitor G04068, Nürnberg, Germany) [25]. A second order function was fit to the luminance data by non-linear regression $\left(r^{2}=99 \%\right)$ :

$L=4.807-0.1887 g+0.0034 g^{2}$,

where $L$ is center screen luminance in $\mathrm{cd} / \mathrm{m}^{2}$ and $g$ is the uniform gray value (range $0-255$ ). These function parameters are incorporated in our stimulus presentation software

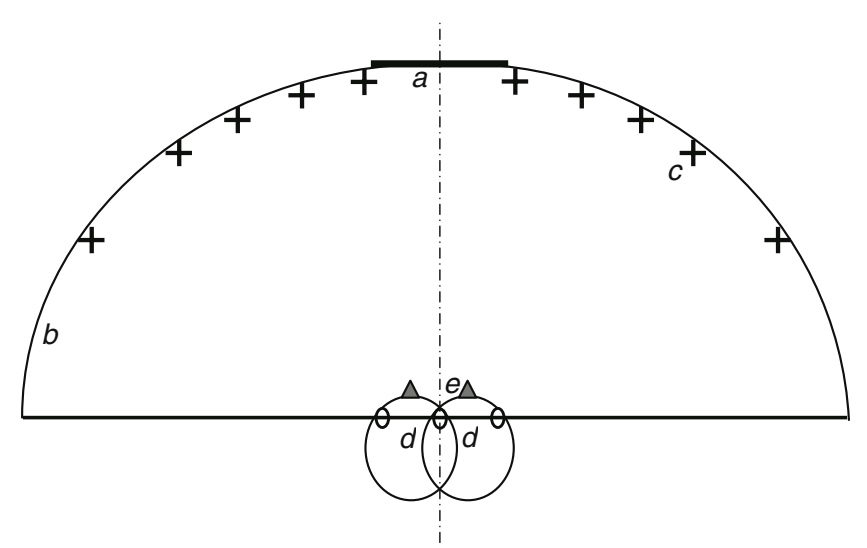

Fig. 1 Experimental set up (top view). The subject's chair was rotated to maintain primary gaze for all tested fixation marks. a LCD monitor screen. b Semicircular plastic screen. c Fixation crosses (diameter= $4 \mathrm{~cm}$, bar width $=0.5 \mathrm{~cm}$ ). d Chin rest for stabilizing the head and keeping the viewing distance constant. e Subject's right or left eye 
(see below). Target contrast is specified in the Michelson measure, $\left(\left(L_{1}-L_{2}\right) /\left(L_{1}+L_{2}\right)\right)$.

\section{Design of the motion stimulus}

The test software for motion perception was customdeveloped for these experiments and consists of two separate modules, one for stimulus generation and another for running the actual test program. Since threshold measurements are much faster and more reliable using four-alternative forced choice than two-alternative forced choice tasks, we employed four directions of motion (up, down, left, and right) to be discriminated by the subject. The stimuli were plaids composed of two orthogonal Gabor patterns of $45^{\circ}$ left and right tilt [15]:

$$
\begin{aligned}
& L(x, y, t)=e^{-\frac{x^{2}+y^{2}}{\sigma_{r}^{2}}} \cos \left(\omega x+\varphi_{x}(t)\right) \cdot \cos \left(\omega y+\varphi_{y}(t)\right)+L_{0} \\
& =e^{-\frac{x^{2}}{\sigma_{x}^{2}}} \cos \left(\omega_{x} x+\varphi_{x}(t)\right) \cdot e^{-\frac{y^{2}}{\sigma_{y}^{2}}} \cos \left(\omega_{y} y+\varphi_{y}(t)\right)+L_{0}
\end{aligned}
$$

where $L$ and $L_{0}$ are the luminances of pattern and background, respectively, $\sigma_{r}^{2}=\sigma_{x}^{2}+\sigma_{y}^{2}$ is the square of radial diameter of the Gaussian envelope (the value where the amplitude has decreased to $1 / \mathrm{e}$ ), and $\varphi(t)$ is the spatial phase at time $t$ (i.e. the shift within the envelope). For the plaids used here, we chose $\sigma=0.8$, which results in about 1.5 visible cycles (Fig. 2).

The subject's task was to identify the direction of motion. Watson found that thresholds of motion detection and motion discrimination in healthy subjects are equal at sufficiently low spatial frequencies (e.g. 2 cpd) for both slow $(1.5 \mathrm{~Hz})$ and fast $(12.4 \mathrm{~Hz})$ movement of the test

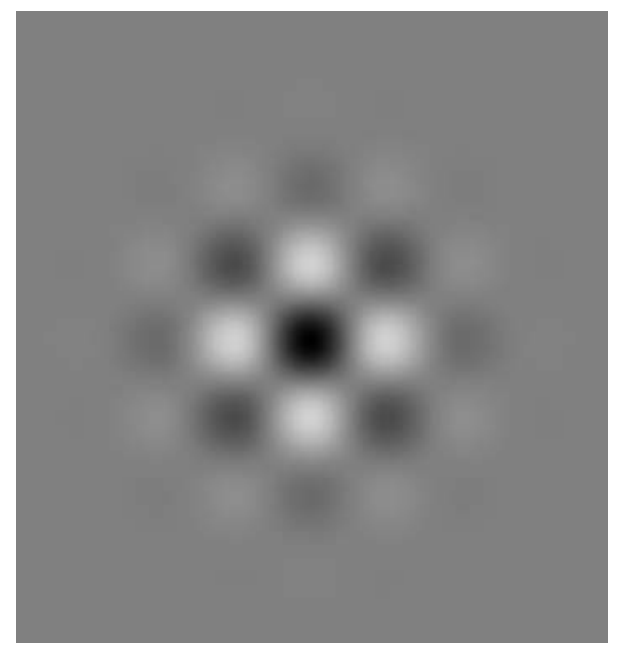

Fig. 2 Gabor stimulus with double sinusoidal modulation in spatial quadrature. The entire patch was stationary, while the plaid pattern moved within the envelope in one of four possible directions. In addition, the stimulus was temporally modulated by a Gaussian envelope function, so that it slowly appeared out of the medium grey background and then merged back into it pattern [63]. Therefore, we used a low spatial frequency of $0.65 \mathrm{cpd}$ and an intermediate speed of $5.71 \%$ (corresponding to $3.75 \mathrm{~Hz}$ local luminance change) for the motion stimulus. The size of the test pattern at the viewing distance of $90 \mathrm{~cm}$ was $3.8^{\circ}$. To minimize attracting transient attention by abrupt pattern onset, the test pattern gradually appeared and disappeared by using a Gaussian temporal envelope $[27,36,37]$. Due to the small changes between frames in these stimuli, "tearing" of the image was extremely unlikely and was indeed never observed [16].

\section{Adaptive algorithm}

Monocular contrast thresholds for motion perception were measured along the horizontal meridian in the nasal and temporal visual field at $10^{\circ}, 20^{\circ}, 30^{\circ}$ and $40^{\circ}$ eccentricity and in the temporal visual field additionally at $60^{\circ}$. The initial contrast value for all eccentricities was 30\% (1.48 log $\%$-contrast). For each eccentricity, the threshold was determined twice. Two blocks of nine measurements each were taken and the arithmetic mean calculated from the two results. The adaptive algorithm for threshold determination was based on Kesten and was modified according to Kaernbach to allow the additional response alternative "I don't know" [28, 29, 32, 58]. This paradigm, termed "unforced choice task" by Kaernbach, has been shown to be beneficial, especially for subjects who are unfamiliar with psychophysical testing procedures.

Kesten's algorithm is of the staircase kind, i.e. the intensity of the next presentation depends on the previous response only, not on the entire history or a longer sequence of preceding responses [32]. After a correct response, the log contrast of the stimulus was decreased by one incremental step, and after an incorrect response, it was increased by 1.67 incremental steps (5/3). It thereby converged on the $62.5 \%$ correct point $(5 / 8)$, i.e. the point of inflection $\varphi$ on the psychometric function (of log contrast) in a four-alternative forced-choice task. The ratio $V=5 / 3=1: 1.667$ of up-down intensity changes results from Kesten's algorithm given the number $n$ of response alternatives (four) by

$V=\frac{\phi}{1-\phi}=\frac{5 / 8}{3 / 8}=\frac{5}{3}$

where $\phi$ is the probability at threshold or point of convergence,

$\phi=\frac{1+\gamma}{2}$

with guessing rate $\gamma=1 / n=1 / 4$. (c.f. Treutwein's equation 16, the last term $\left(Z_{n}-\varphi\right)$ [58]). When the subject gave the indecisive response "I don't know", the intensity of the next stimulus was increased by one incremental step, as specified by Kaernbach's extension which requires the specification of 
$V$ as above [28]. The step width in Kesten's algorithm is reduced by a factor of $m /(m+2)$ after a change in response category (correct-to-incorrect or vice versa) where $m$ is the number of reversals (Treutwein's eq. 16). Since Kaernbach's extension requires the above-mentioned fixed ratio of updown intensity changes, we used a step width reduction only every other reversal (i.e. $m$ even). The Kesten rule is applied to $\log$ contrast, i.e. $\log C_{n+1}=\left(\log C_{n}\right) \pm s_{n}$ (where $s_{n}$ is the step width), which is equivalent to contrast being multiplied or divided by the antilog of step width.

\section{Double-pulse resolution}

Treutwein and Rentschler developed a hardware and software combination for the measurement of double-pulse resolution (DPR) which allows simultaneous measurement at multiple visual field positions [60]. The technique has been used in experiments on patients with multiple sclerosis and glaucoma, and in an extensive study characterizing the temporal properties of the visual field across the life span [46, 48-50]. The experimental setup allowed (limited by screen size) measurement of DPR up to $20^{\circ}$ eccentricity, i.e. not as far into the periphery as for the motion contrast thresholds but well beyond the macular region.

\section{Test setup}

An analogue 15" x-y-z display was used for stimulus presentation (Hewlett Packard model 1310, i.e. a CRT-display without a raster-scan generator), driven by a temporary buffer that stores the point coordinates and generates the control voltages for the display ("point plot buffer"; G. Finlay,
Edmonton, Canada). Temporal control could be extended into the low microsecond range, so that the temporal resolution was better by a factor of 1,000 than in conventional setups [60]. A computer (PC) was used for running the experimental software that controlled stimulus generation, adaptive procedure, and data acquisition. The experimenter recorded the subject's responses via the computer keyboard.

\section{Stimulus characteristics}

The tests were performed monocularly at $30 \mathrm{~cm}$ viewing distance with a diagonal screen diameter of $40 \mathrm{~cm}$. The stimuli in Treutwein's technique are eight squares of $1.15^{\circ} \times 1.15^{\circ}$ visual angle $(5 \times 5$ pixels $)$ each, arranged in circles at $5^{\circ}, 10^{\circ}$, and $20^{\circ}$ eccentricity around a ninth square in the center [60]. Figure 3 shows the stimulus time course. Eight of nine squares are continuously present for $80+\gamma+280 \mathrm{~ms}$. The target, one randomly selected stimulus, is switched off after $80 \mathrm{~ms}$ and then on again after a variable time gap $\gamma$. The subject's task was to detect the gap and indicate the target position on the screen, which makes it a nine-alternative forced choice task. In supra-threshold trials, its location can be recognized as a short flicker of the target. A central fixation cross was presented continuously between stimulus presentations and was switched off $50 \mathrm{~ms}$ before the beginning of a new trial. The squares' luminance was $215 \mathrm{~cd} / \mathrm{m}^{2}$; subjects were light-adapted and the display background luminance was held constant in the low photopic range (luminance $\sim 15 \mathrm{~cd} / \mathrm{m}^{2}$ ).

Gap duration was varied by an adaptive thresholding algorithm ("YAAP"), based on maximum-likelihood psychometric function fitting [20, 59].
Fig. 3 Double-pulse stimulus characteristics (figure modified after Poggel and Strasburger, originally from Treutwein and Rentschler [46, 60]. a, b Time line diagram of stimulus display. c Stimulus positions $\left(5^{\circ}, 10^{\circ}\right.$, and $20^{\circ}$ eccentricity)

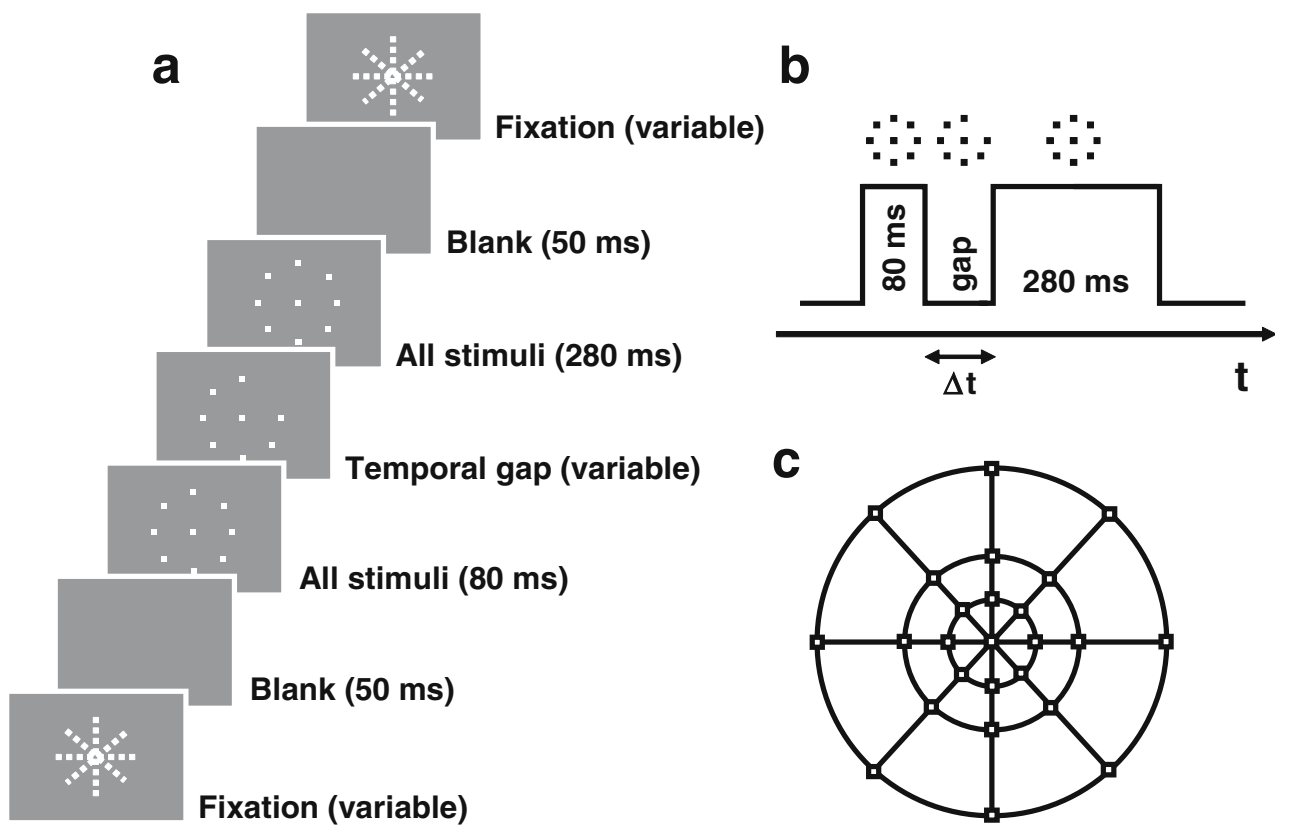


Flicker frequency analyzer

For measurement of foveal flicker fusion frequencies we used the "Wiener Testsystem", a commercial computerbased diagnostic system with an emphasis on assessing driving fitness (Schuhfried, Moedling/Vienna, Austria). The system was chosen as a reference, because it is an established standard system in Germany used for psychological testing; due to its construction it allows foveal measurement only. Measurements were performed by presenting a circular flickering red light stimulus $\left(1.2^{\circ}\right.$ diameter; luminance $=270 \mathrm{~cd} / \mathrm{m}^{2}$; wave length $655 \mathrm{~nm}$ ) on a white background in a tubular viewer. Thresholds were determined by the method of limits, i.e. the frequency of the flickering light is increased until permanent light is perceived and is then decreased until the light is once again perceived as flickering.

The subject indicated the perceived changes by a keystroke whereupon the critical frequency was recorded. The separate arithmetic means of the critical frequencies determined in the ascending and descending series are referred to as fusion frequency and flicker frequency, respectively. Each test cycle consisted of five training cycles, immediately followed by eight measurement cycles. For further analysis, the mean of the fusion frequency and the flicker frequency was calculated for each subject, which is referred to as the critical flicker fusion frequency (CFF).

\section{Color perception}

The Lanthony D-15 color vision test (desaturated) was used for the examination of color perception. The test consists of 15 colored chips, which are used to determine the subject's capability to discriminate hues. At $50 \mathrm{~cm}$ viewing distance, every chip has a diameter of about $1.5^{\circ}$. The subject sorts the arbitrarily shuffled chips according to the arrangement in the color cycle. The chosen sequence was then documented in a test protocol and the color confusion score (CCS) and crossings over the color space were determined [1]. The measurement was done once under constant lighting conditions (color temperature $4000 \mathrm{~K}$ ).
Subjects

We recruited three groups of subjects for this study: 14 subjects with ARM (19 eyes, mean visual acuity: 0.29, $\mathrm{SE} \pm$ 0.048; 20/63), a control group of age-matched subjects with healthy eyes (14 subjects; 18 eyes, mean acuity: 0.65 , $\mathrm{SE} \pm 0.057 ; \sim 20 / 32$ ), and another control group of 7 young subjects ( 8 eyes, mean acuity: $1.25, \mathrm{SE} \pm 0.047 ; 20 / 16$ ) (Table 1). ARM in 16 of the 19 eyes of patients were classified as "dry" and three as "wet". Six of 19 eyes in the ARM group had received intra-ocular lens implants during cataract surgery, which was also the case for 14 out of the 18 eyes of the age-matched control group. Since in most cases the implant causes mild myopia $(-0.5 \mathrm{dpt})$, the patients-though presbyopic-could observe the fixation mark comfortably without near correction. Thus, optical artifacts from eyeglasses were prevented, such as aberrations or interference from the glasses' rims, which would otherwise occur at higher eccentricities.

Visual acuity (VA) was measured by a Landolt ring test (Binoptometer, Oculus, Germany) at $90 \mathrm{~cm}$ viewing distance $\left(\mathrm{VA}=1 / \omega^{\prime}\right.$, where $\omega^{\prime}$ is the minimum angle of resolution in minutes). Based on these values, all subjects were capable of directing their gaze at the fixation mark without glasses. All subjects with ARM and the agematched control group provided an up-to-date medical statement from an ophthalmologist, which appraised the condition of the retina and excluded other eye diseases (e.g. glaucoma, secondary cataract). All subjects were examined by their ophthalmologist with respect to clarity of the optical media, and none of them showed any evidence of changes in the visual pathways.

The complete examination (including the initial interview) took approximately 3 hours.

The ages of the subjects with ARM and the age-matched controls were sufficiently close; a t-test with a preceding test for normal distribution showed that the two groups did not differ significantly with respect to their age $(p=0.36)$. The study design had been approved by the ethics committee of the University of Munich and testing procedures were in accordance with the tenets of the Declaration of Helsinki. All subjects gave their informed consent for participation.

Table 1 Age and visual acuity of the subject groups

\begin{tabular}{|c|c|c|c|c|c|c|c|}
\hline & \multirow[b]{2}{*}{$N$} & \multicolumn{4}{|l|}{ Age } & \multicolumn{2}{|l|}{ Visual acuity } \\
\hline & & Mean & $\mathrm{SE}$ & Minimum & Maximum & Mean & SE \\
\hline ARM group & 19 & 73.79 & 2.3 & 60 & 90 & $0.29(20 / 63)$ & 0.048 \\
\hline Age-matched controls & 18 & 71.5 & 1.5 & 60 & 78 & $0.65(20 / 32)$ & 0.057 \\
\hline Young controls & 8 & 27.1 & 1.7 & 21 & 34 & $1.25(20 / 16)$ & 0.047 \\
\hline
\end{tabular}

Visual acuity is described in decimal notation and Snellen fractions 


\section{Results}

Motion contrast threshold

Figure 4 shows the contrast thresholds for motion perception as a function of eccentricity in the visual field. Compared with the age-matched controls, the ARM group shows a distinct increase of contrast thresholds up to $20^{\circ}$ in the nasal and up to $40^{\circ}$ in the temporal field. Mann-Whitney U-tests of the contrast thresholds at $10^{\circ}, 20^{\circ}, 30^{\circ}$, and eccentricity on the horizontal meridian each showed significant differences between the two elderly groups (Table 2).

\section{Double-pulse resolution}

With respect to double-pulse resolution, the subjects with ARM showed strongly increased thresholds compared with the age-matched controls within the $20^{\circ}$ visual field covered by the test area (Fig. 5). For better comparison with the motion sensitivity data, Fig. 6 also shows the double-pulse results on the horizontal meridian. Both the comparison on the two horizontal meridians and on the entire circles at the investigated eccentricities $\left(5^{\circ}, 10^{\circ}\right.$, and $\left.20^{\circ}\right)$ show significant group differences. We performed a Mann-Whitney U-test at every position on the horizontal visual field meridian (Table 3).

\section{Critical flicker fusion frequency (CFF)}

Figure 7 shows critical flicker fusion frequency (CFF) as a function of age for the three subject groups. There is a slight but significant $(\mathrm{p}<0.05)$ loss of CFF with age. It amounts to $0.059 \mathrm{~Hz}$ per year of age (i.e. around $5 \mathrm{~Hz}$ for the entire life span), which accounts for $30 \%$ of the interindividual variance in the healthy subjects. Age-independent interindividual variance $(70 \%)$ thus far exceeds the agerelated loss. More importantly here, however, the graph also shows the marked loss of performance in the subjects with ARM. On average, the CFF in the ARM group is lower by $5.47 \mathrm{~Hz}$, or approximately $14 \%$, in comparison to the age-matched controls. Note that one 90-year-old subject reached the level of young normal subjects, while all other subjects with ARM showed lower performance than all young controls.

The analysis of variance (one-way ANOVA with group as factor and post-hoc test, Tamhane procedure) indicates a highly significant difference between the three groups ( $F=$ 25.16; $\mathrm{df}=2 ; p<0.001)$ which was caused predominantly by the highly significant difference between the age-matched control group and the ARM group $(p<0.001)$.

\section{Color perception}

Performance in color perception is a sensitive indicator of differential impairment of the parvo- vs. the magnocellular system [31]. The result from the Lanthony D-15 color vision test (unsaturated) allows the calculation of the color confusion score (CCS), which was used for the statistical analysis of the results. A one-way ANOVA with subject groups as factor and subsequent post-hoc test (Tamhane procedure) showed highly significant differences $(F=$ 25.285; $\mathrm{df}=2 ; p<0.001)$ between the three test groups. The difference between the age-matched control group and the ARM group was also highly significant $(p<0.001)$. Thus, the subjects with ARM clearly showed impaired color discrimination. The comparison of crossings over the color space also shows significant differences between the subject groups $(F=20.394 ; \mathrm{df}=2 ; p<0.001$; mean crossings: $A R M=5.81$, age-matched controls $=1.78$, and young controls $=0$ ).
Fig. 4 Mean contrast thresholds for motion perception of the subjects with ARM, agematched controls, and young controls on the horizontal meridian. The broken lines show the increased contrast thresholds when stimuli were presented near the blind spot. The continuous lines show the regression (specified in the formula); omitted for the age-matched control group on the temporal side for clarity

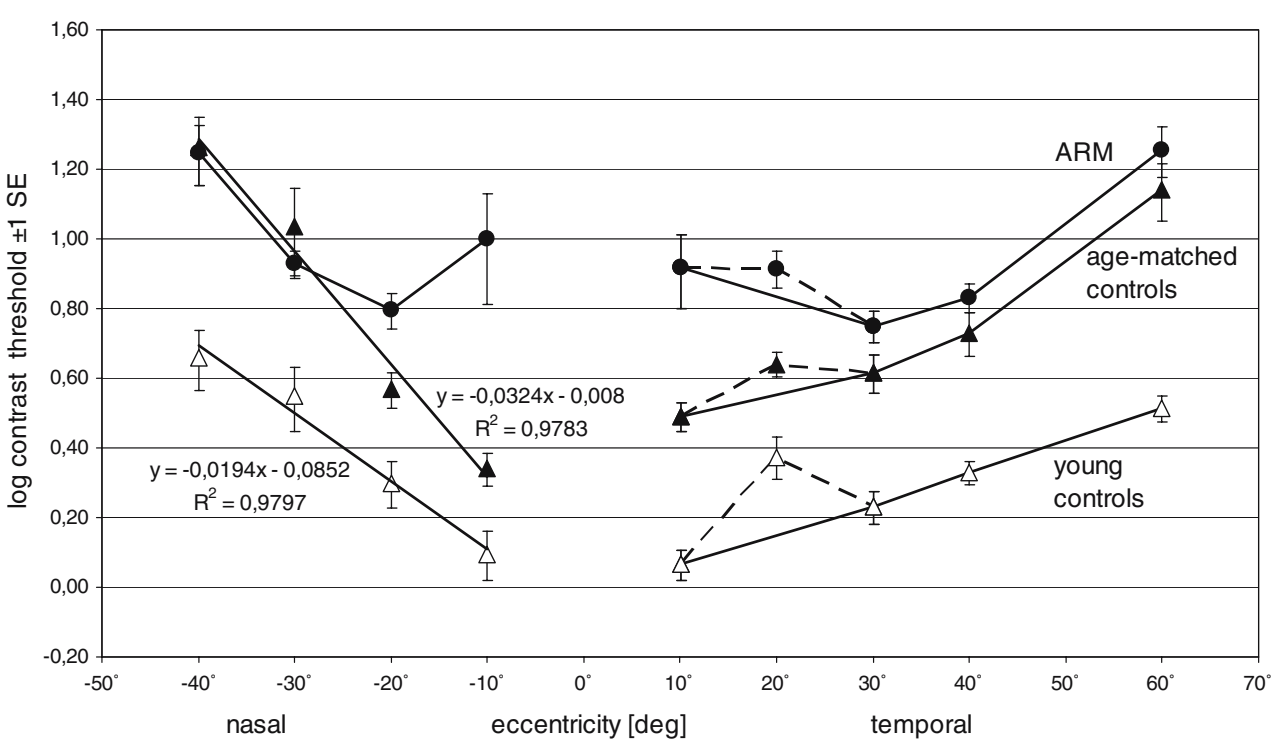


Table 2 Results of Mann-Whitney U-tests of contrast thresholds (ARM group vs. age-matched control group); $U$ is the statistical value of non-parametric Mann-Whitney test for comparison of independent samples based on ordinal ranks; $z$ is the estimated statistical value of normalized distribution of $U$ values; $p$ is the significance level

\begin{tabular}{|c|c|c|c|c|c|c|}
\hline \multirow[t]{2}{*}{ Eccentricity } & \multicolumn{3}{|c|}{ Nasal field } & \multicolumn{3}{|c|}{ Temporal field } \\
\hline & $U$ & $z$ & $p$ & $U$ & $z$ & $p$ \\
\hline $10^{\circ}$ & 16.00 & -4.71 & $<0.001$ & 53.00 & -3.59 & $<0.001$ \\
\hline $20^{\circ}$ & 69.50 & -3.09 & 0.002 & 72.50 & -2.83 & 0.005 \\
\hline $30^{\circ}$ & 148.50 & -0.68 & 0.49 & 96.00 & -2.28 & 0.023 \\
\hline $40^{\circ}$ & 145.50 & -0.25 & 0.80 & 102.00 & -2.10 & 0.036 \\
\hline $60^{\circ}$ & - & - & - & 134.00 & -1.12 & 0.261 \\
\hline
\end{tabular}

\section{Discussion}

\section{Motion perception}

Our findings document deficits of dynamic visual field properties in ARM in a retinal region that extends far beyond the macula. In a sense, the well documented loss of visual function (e.g. foveal acuity) in the macula of subjects with ARM seems just like the proverbial tip of an iceberg. To our knowledge, this is the first study of dynamic characteristics of the peripheral visual field up to $60^{\circ}$ eccentricity in subjects with ARM. Functional studies on these patients in the past have either concentrated on foveal function only, or have used a large central stimulus that did not discriminate between foveal and nonfoveal function [5, 40-42, 57]. Only the study by Brown and Lovie-Kitchen has shown deficits in the temporal visual field up to $20^{\circ}$ eccentricity [13].

There are only a few studies on dynamic processing characteristics in ARM. Mayer et al. measured flicker sensitivity only foveally and suggest that it can be a predictor of exudative ARM [40, 41]. Normal aging of visual function - from which ARM losses need to be distinguished - has received only limited attention $[19,45,46,61]$.

In the present study, we determined the contrast thresholds for motion perception far into the periphery of the visual field on the horizontal meridian, up to $40^{\circ}$ on the nasal, and $60^{\circ}$ on the temporal side. We found pronounced impairment in the ARM group up to $20^{\circ}$ nasally and $30^{\circ}$ temporally, and smaller impairments still further out on the temporal side. The macula is commonly described as having a radius of $10^{\circ}[2,22]$. These elevated contrast thresholds for motion perception extend far beyond this eccentricity, in conflict with a widespread assumption that the effects of manifest ARM are restricted to the macula. The latter seems to be based on two facts. First, customary descriptions and classifications of the disease use morphological features that are visible by ophthalmoscopy or on fundus photographs [6-8]; and second, many experimental studies have tested vision in subjects with ARM only in central locations in the visual field as noted above, with a few notable exceptions $[10,11,55]$.
Fig. 5 Mean double-pulse resolution (DPR) of the ARM group, age-matched controls and young controls at $5^{\circ}, 10^{\circ}$, and $20^{\circ}$ eccentricity (stimuli positioned on concentric rings, Fig. 3). The $0^{\circ}$-value represents the foveal DPR in the $5^{\circ}$-ring measurement. Note that the rather small SEM error bars indicate a limited range of variation of values

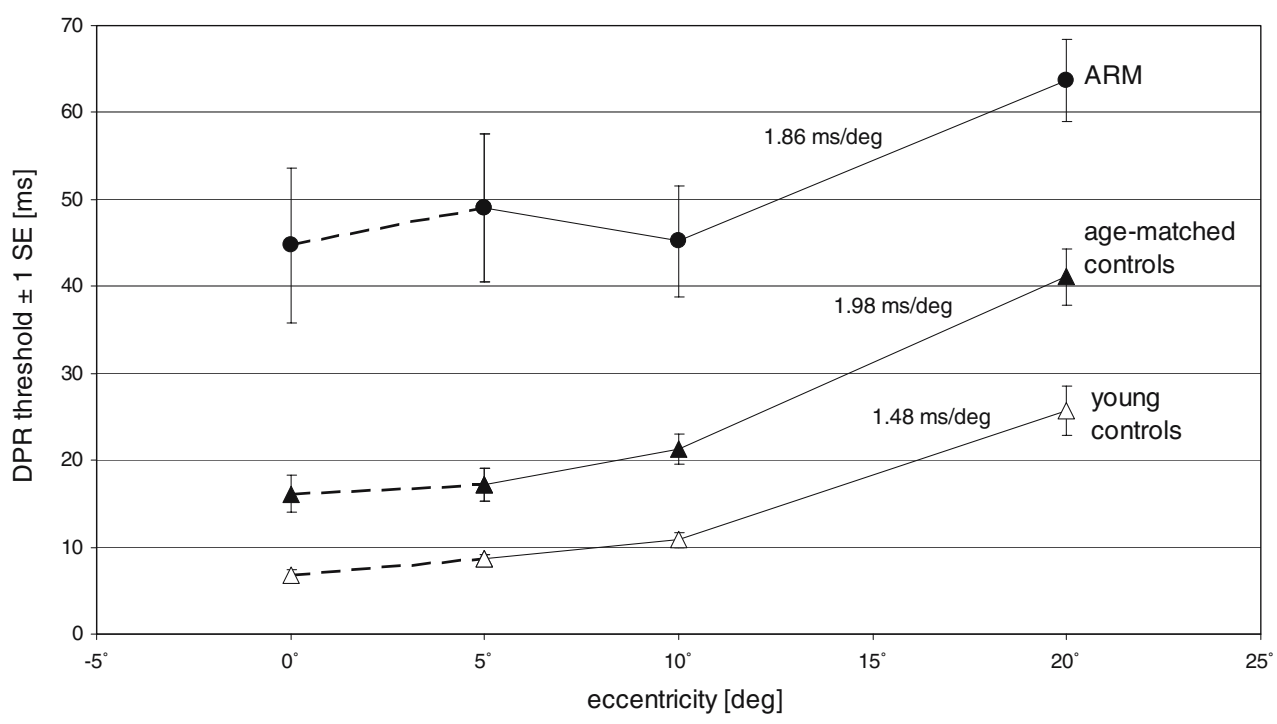


Fig. 6 Double-pulse resolution (DPR) of the ARM group, agematched controls, and young controls along the horizontal meridian

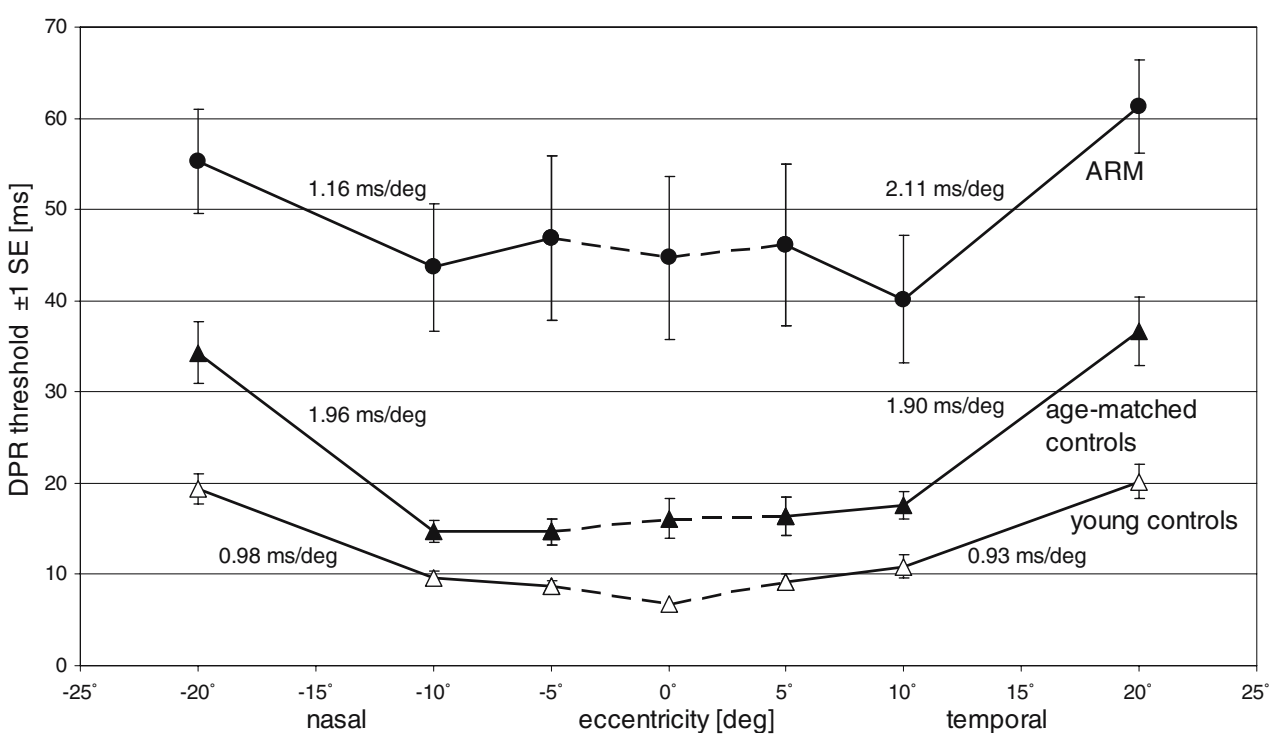

In clinical practice, the assessment of the visual periphery is believed to play a minor role in ARM, for a lack of consequences in ophthalmic treatment and also because of the dramatic vision loss from damage to the central retina, immediately noticed by patients who report the loss of the ability to recognize fine spatial or contrast detail (e.g. small print). A loss of peripheral motion sensitivity, in contrast, is not easily recognized by the patient, possibly because the conscious (sustained) component of attention is normally directed towards central vision, whereas the transient (reflex-like) component of attention is not accessible by consciousness [44]. This phenomenon plays a well-known role in glaucoma which often goes unnoticed by the patient. Thus, the fact that patients do not complain about deficits in peripheral motion perception might lead the practitioner not to examine this retinal region in detail. Yet, practical consequences have to be considered. If diminished sensitivity to motion raises the possibility that a patient's transient attention might not be attracted to a moving stimulus, a behaviorally valuable eye movement may not be performed and a potentially hazardous situation may not be recognized.

Table 3 Results of Mann-Whitney U-tests at each eccentricity for the ARM group and the age-matched control group; $U$ is the statistical value of non-parametric Mann-Whitney test for comparison of
Additionally, the tests available in routine clinical practice do not provide the appropriate stimuli to detect such defects. For instance, Holopigian et al. examined peripheral vision in patients with early ARM using standard electrophysiological and psychophysical tests (dark adaptation curves, electro-oculograms and electro-retinograms [23]. They found that only few subjects with early ARM developed disease-related effects in this region when examined with standard clinical tests.

Double-pulse resolution (DPR) and critical flicker fusion (CFF)

The results of DPR revealed distinct and statistically significant differences between the ARM group and agematched controls up to $20^{\circ}$ eccentricity. Furthermore, the increased foveal thresholds of double-pulse resolution in subjects with ARM parallel the elevated foveal CFF thresholds, which also show a dependency on age and a significant increase in subjects with ARM.

Comparison of the age-matched with the young control group shows an age dependency which confirms earlier

independent samples based on ordinal ranks; $z$ is the estimated statistical value of normalized distribution of $U$ values; $p$ is the significance level

\begin{tabular}{|c|c|c|c|c|c|c|}
\hline \multirow[t]{2}{*}{ Eccentricity } & \multicolumn{3}{|c|}{ Nasal field } & \multicolumn{3}{|c|}{ Temporal field } \\
\hline & $U$ & $z$ & $p$ & $U$ & $z$ & $p$ \\
\hline $5^{\circ}$ & 46.50 & -2.55 & 0.011 & 46.50 & -2.56 & 0.011 \\
\hline $10^{\circ}$ & 45.00 & -3.83 & $<0.001$ & 79.50 & -2.78 & 0.005 \\
\hline $20^{\circ}$ & 76.00 & -2.89 & 0.003 & 61.00 & -3.34 & 0.001 \\
\hline
\end{tabular}


Fig. 7 Critical flicker fusion frequency as a function of age for the three groups. The regression line refers to the healthy controls

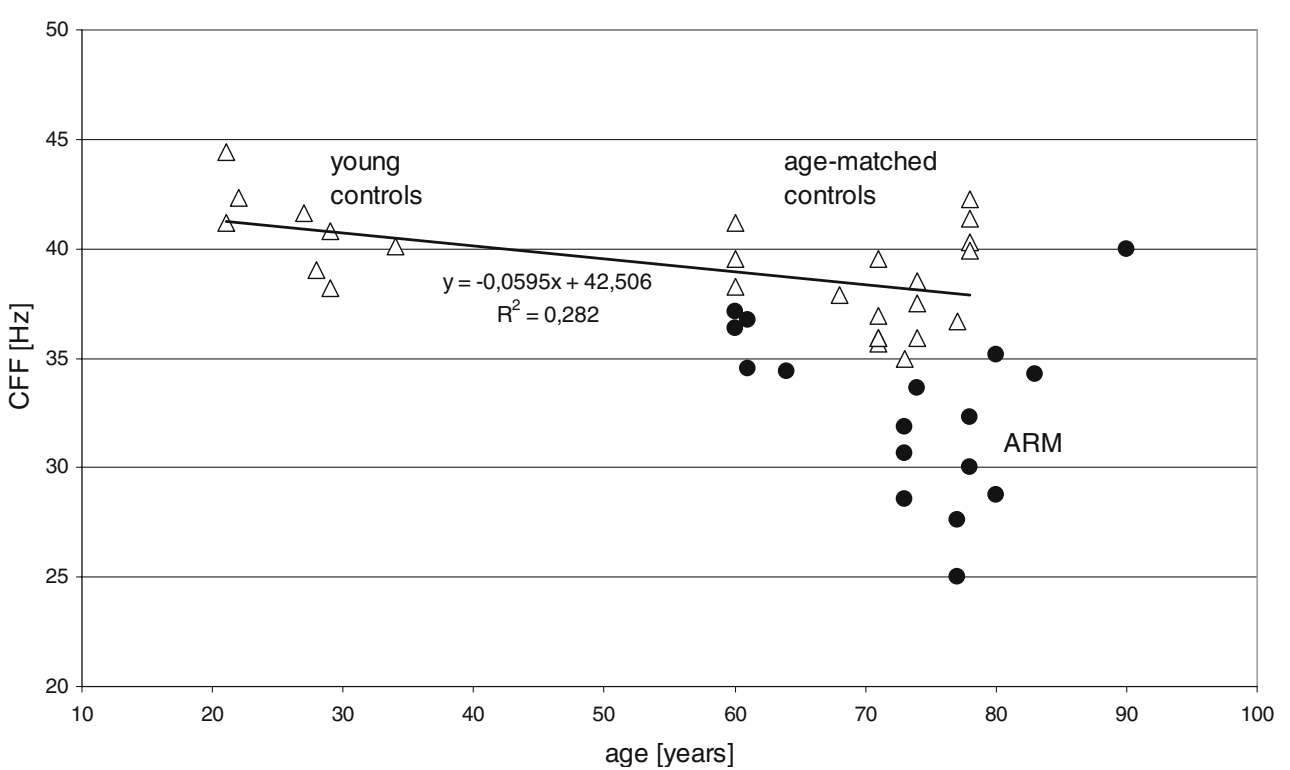

results $[18,46,48,61]$. However, our results cannot be directly compared with the findings of Falsini et al. [13] who used a large homogeneous test field ( $18^{\circ}$ diameter) that covered visual field regions with pronounced differences in functional characteristics.

The fact that reduced dynamic performance in our patients was found for two quite different methods of measurement emphasizes the presence of impaired temporal vision performance far beyond the macula and suggests a common underlying pathogenesis.

\section{Color vision}

The objective of the color vision test was to examine the relative involvement of the two neuronal subsystems of the primary visual pathway - magnocellular (M) and parvocellular $(\mathrm{P})$ - in the previously obtained results. Both motion perception and temporal resolution are assumed to be predominantly conveyed by the $\mathrm{M}$ system, whereas color vision is predominantly mediated by the $\mathrm{P}$ system [31]. To simply find out whether color perception is intact, it is legitimate to use the color vision test foveally, or to allow the subjects to use the retinal area that serves them best. A (seemingly self-evident) conclusion that the deficits reported here may be caused by a specific damage to the $\mathrm{M}$ system can thus be rejected. Impaired color vision, as found here, shows that the P system is also affected.

The ARM group in our study showed a significantly lower foveal color vision performance than the agematched control group. This would seem in conflict with the results of Frennesson et al. and Medina et al. who found no color vision deficits in subjects with ARM at an early stage $[14,42]$. However, those studies used less sensitive tests with saturated colors, such as the Farnsworth D-15 test or the Farnsworth-Munsell 100 Hue test, whereas our findings are based on the more sensitive Lanthony D-15 test which uses unsaturated colors [14, 42]. Since (static) contrast sensitivity was not measured here, we cannot estimate how strongly the color vision findings were influenced by the expectedly reduced contrast sensitivity of these patients.

\section{Consequences}

Even though the perceptual limitations measured in this study are not immediately evident to subjects with ARM, their relevance for daily life should not be underestimated. Their importance is due especially to the fact that segments of the near periphery assist safe mobility in general and driving a car in particular [21, 39]. Visual perception of moving stimuli has two functions of great importance in daily life. First, we perceive a stable, stationary world in which we are moving, despite the fact that nearly all image components on the retina are moving [43]. Being able to distinguish between the effects of self-motion and those of moving objects requires the detection and analysis of relative motion [47]. Second, our attention is constantly redirected to interesting and potentially dangerous objects, which typically cause a reorientation of gaze. These functions were examined previously in connection with the distinction between sustained and transient attention [3, 38, 44].

Because of the impairment of the central visual field in ARM, motion perception with peripheral vision is of even greater importance for these patients. Measurements with dynamic test stimuli are especially important for the assessment of driving ability of visually impaired persons [24]. Marron and Bailey examined contrast sensitivity and 
visual acuity with regard to their importance for orientation and mobility [39]. Their results provide evidence that contrast sensitivity and the integrity of the visual field are of considerably greater importance for safe mobility than visual acuity. Studies from our own group show that dynamic peripheral sensitivity in a divided attention condition was the strongest predictor for safe driving in a group of healthy elderly drivers [53]. Recent studies have confirmed the importance of peripheral vision for driving by finding that contrast sensitivity and visual field limitations are the strongest predictors for mobility of visually impaired persons $[10,21,35]$. These studies demonstrate the importance of the assessment of visually guided performance regarding moving objects and contrast vision. In the tests at hand, these two tasks are linked. The growing possibilities for mobility of the elder generation with age-related visual impairment require examinations that take into account seniors' new lifestyles and can help ensure safe navigation.

Another relevant connection can be made with communication and the ability to read speech from the lips of a conversation partner, which is a difficulty faced by many elderly with additional hearing impairment. Although a general notion of the role of vision in speechreading has been established [56], the importance of motion sensitivity for speechreading has not been sufficiently investigated to date.

Acknowledgements We thank A. Gofen (The Smith-Kettlewell Eye Research Institute, San Francisco) who programmed the motion sensitivity test supported by a grant to Manfred MacKeben, Ph.D. from the Beatrice Brandes Low Vision Research Fund. Thanks are also due to B. Treutwein, M.D., University of Munich, for generous support with his Double-Pulse Resolution technique, and G. Haegerstrom-Portnoy O.D., Ph.D., UC Berkeley, School of Optometry, for the software to calculate the color perception results. We thank Prof. Ernst Pöppel for the space and encouragement to pursue this research. D. Poggel, Ph.D. was supported by a grant of the Deutsche Forschungsgemeinschaft to Hans Strasburger (STR 354/3-1). W. Eisenbarth, Ph.D. was supported by a travel grant to visit the ARVO meeting 2004, funded by the German Zentralverband für Augenoptiker.

\section{References}

1. Adams AJ, Haegerstrom-Portnoy G (1987) Color deficiency. In: Amos JF (ed) Diagnosis and management in vision care. Butterworths, Stoneham

2. Alm A, Ehinger BEJ (2003) Retina. In: Kaufman PL, Alm A (eds) Adler's physiology of the eye. Mosby, St. Louis, p 319-422

3. Altpeter E, MacKeben M, Trauzettel-Klosinski S (2000) The importance of sustained attention for patients with maculopathies. Vis Res 40:1539-1547

4. Bach M, Meigen T, Strasburger H (1997) Raster-scan cathode-ray tubes for vision research-limits of resolution in space, time and intensity, and some solutions. Spat Vis 10:403-414

5. Bartlett H, Eperjesi F (2003) A randomised controlled trial investigating the effect of nutritional supplementation on visual function in normal, and age-related macular disease affected eyes: design and methodology. Nutr J 2:12

6. Bird AC, Bressler NM, Bressler SB, Chisholm IH, Coscas G, Davis MD, de Jong PT, Klaver CC, Klein BE, Klein R (1995) An international classification and grading system for age-related maculopathy and age-related macular degeneration. The International ARM Epidemiological Study Group. Surv Ophthalmol 39:367-374

7. Bressler S, Bressler N, Gragoudas E (1994) Age-related macular degeneration: choroidal neovascularization. In: Albert DM, Jakobiec FA (eds) Principles and practice of ophthalmology. WB Saunders Company, Philadelphia

8. Bressler SB, Bressler NM, Gragoudas ES (1994) Age-related macular degeneration: Drusen and geographic atrophy. In: Albert DM, Jakobiec FA (eds) Principles and practice of ophthalmology. WB Saunders Company, Philadelphia, p 826-852

9. Brown B, Adams AJ, Coletta NJ, Haegerstrom-Portnoy G (1986) Dark adaptation in age-related maculopathy. Ophthalmic Physiol Opt 6:81-84

10. Brown B, Brabyn L, Welch L, Haegerstrom-Portnoy G, Colenbrander A (1986) Contribution of vision variables to mobility in age-related maculopathy. Am J Optom Physiol Opt 63:733-739

11. Brown B, Lovie-Kitchin JE (1987) Temporal function in agerelated maculopathy. Clin Exp Optom 70:112-116

12. Curcio C, Medeiros NE, Millican CL (1996) Photoreceptor loss in age-related macular degeneration. Investig Ophthalmol Vis Sci 37:1236-1249

13. Falsini B, Fadda A, Iarossi G, Piccardi M, Canu D, Minnella A, Serrao S, Scullica L (2000) Retinal sensitivity to flicker modulation: reduced by early age-related maculopathy. Invest Ophthalmol Vis Sci 41:498-506

14. Frennesson C, Nilsson UL, Nilsson SE (1995) Colour contrast sensitivity in patients with soft drusen, an early stage of ARM. Doc Ophthalmol 90:377-386

15. Gabor D (1946) Theory of communication. J Inst Electr Eng 93 (III):429-457

16. Gofen A, MacKeben M (1997) An introduction to accurate display timing for PCs under 'Windows'. Spat Vis 10:361-368

17. Goldberg J, Flowerdew G, Smith E, Brody JA, Tso MO (1988) Factors associated with age-related macular degeneration. An analysis of data from the first National Health and Nutrition Examination Survey. Am J Epidemiol 128:700-710

18. Haegerstrom-Portnoy G, Schneck ME, Brabyn JA (1999) Seeing into old age: vision function beyond acuity. Optom Vis Sci 76: $141-158$

19. Hammond BJ, Wooten B (2005) CFF thresholds: relation to macular pigment optical density. Ophthalmic Physiol Opt 25 (4):315-319

20. Harvey LO Jr (1986) Efficient estimation of sensory thresholds. Behav Res Meth Instr Comp 18:623-632

21. Hassan SE, Lovie-Kitchin JE, Woods RL (2002) Vision and mobility performance of subjects with age-related macular degeneration. Optom Vis Sci 79:697-707

22. Hogan MJ, Alvarado JA, Weddell JE (1971) Histology of the human eye. W. B. Saunders, Philadelphia

23. Holopigian K, Seiple W, Greenstein V, Kim D, Carr RE (1997) Relative effects of aging and age-related macular degeneration on peripheral visual functions. Optom Vis Sci 74:152-159

24. Hyvärinen L (1999) Visual perception in "low vision". Perception 28:1533-1537

25. Irtel H (1997) PXL: a library for psychological experiments on IBM PC type computers. Spat Vis 10:467-469

26. Jonasson F, Thordarson K (1987) Prevalence of ocular disease and blindness in a rural area in the eastern region of Iceland during 1980 through 1984. Acta Ophthalmol Scand 182(suppl):40-43 
27. Jonides J, Yantis S (1988) Uniqueness of abrupt visual onset in capturing attention. Percept Psychophys 43:346-354

28. Kaernbach C (2001) Adaptive threshold estimation with unforcedchoice tasks. Percept Psychophys 63:1377-1388

29. Kaernbach C (1991) Simple adaptive testing with the weighted up-down method. Percept Psychophys 49:227-229

30. Kahn HA, Leibowitz HM, Ganley JP, Kini MM, Colton T, Nickerson RS, Dawber TR (1977) The Framingham Eye Study. II. Association of ophthalmic pathology with single variables previously measured in the Framingham Heart Study. Am J Epidemiol 106:33-41

31. Kaplan E, Lee BB, Shapley RM (1990) New views of primate retinal function. In: Osborne N, Chader J (eds) Progress in retinal research. Pergamon Press, Oxford, p 273-336

32. Kesten H (1958) Accelerated stochastic approximation. Ann Math Stat 29:41-59

33. Klein R, Klein BE, Linton KL (1992) Prevalence of age-related maculopathy. The Beaver Dam Eye Study. Ophthalmology 99:933-943

34. Klein R, Peto T, Bird A, Vannewkirk M (2004) The epidemiology of age-related macular degeneration. Am J Ophthalmol 137:486-495

35. Kuyk T, Elliott JL (1999) Visual factors and mobility in persons with age-related macular degeneration. J Rehabil Res Dev 36:303-312

36. Lappin JS, Craft WD (2000) Foundations of spatial vision: from retinal images to perceived shapes. Psychol Rev 107:6-38

37. Lappin JS, Tadin D, Whittier EJ (2002) Visual coherence of moving and stationary image changes. Vis Res 42:523-534

38. MacKeben M, Nakayama K (1993) Express attentional shifts. Vis Res 33:85-90

39. Marron JA, Bailey IL (1982) Visual factors and orientationmobility performance. Am J Optom Physiol Opt 59:413-426

40. Mayer MJ, Spiegler SJ, Ward B, Glucs A, Kim CB (1992) Mid-frequency loss of foveal flicker sensitivity in early stages of age-related maculopathy. Investig Ophthalmol Vis Sci 33:3136-3142

41. Mayer MJ, Ward B, Klein R, Talcott JB, Dougherty RF, Glucs A (1994) Flicker sensitivity and fundus appearance in pre-exudative age-related maculopathy. Investig Ophthalmol Vis Sci 35:1138-1149

42. Midena E, Degli Angeli C, Blarzino MC, Valenti M, Segato T (1997) Macular function impairment in eyes with early age-related macular degeneration. Investig Ophthalmol Vis Sci 38:469-477

43. Nakayama K, Loomis JM (1974) Optical velocity patterns, velocity-sensitive neurons, and space perception: a hypothesis. Perception 3:63-80

44. Nakayama K, MacKeben M (1989) Sustained and transient components of focal visual attention. Vis Res 29:1631-1647

45. Owsley C, Sekuler R, Siemsen D (1983) Contrast sensitivity throughout adulthood. Vis Res 23:689-699

46. Poggel DA, Strasburger H (2004) Visual perception in time and space-mapping the visual field of temporal resolution. Acta Neurobiol Exp 64:427-437
47. Poggel DA, Strasburger H, MacKeben M (2007) Cueing attention by relative motion in the periphery of the visual field. Perception 36(7):955-970

48. Poggel DA, Treutwein B, Calmanti C, Strasburger H (2005) The Toelz temporal topography study: mapping the visual field across the life span. J Vision 4(11):76

49. Sachs H (1995) Die Erkennbarkeit zeitlicher Doppelpulse im zentralen Gesichtsfeld: Grundlagen und klinische Anwendung. Akademischer Verlag, München

50. Stelmach LB, Drance SM, Di Lollo V (1986) Two-pulse temporal resolution in patients with glaucoma, suspected glaucoma, and in normal observers. Am J Ophthalmol 102:617-620

51. Strasburger H (ed) (1997) Use of computers and cathode-ray-tube displays in visual psychophysics. Part I. VSP, AH Zeist, The Netherlands

52. Strasburger H (ed) (1997) Use of computers and cathode-ray-tube displays in visual psychophysics. Part II. VSP, AH Zeist, The Netherlands

53. Strasburger H, Grundler W, Burgard E (2006) Kognitive Tests aussagekräftiger. Studien zur Validierung von Instrumenten der Seh- und Eignungsdiagnostik. (Cognitive tests are more predictive: Validation of instruments for assessing driving fitness.) Ophthalmologische Nachrichten 09/2006, Kongressausgabe 2:30

54. Strasburger H, Wüstenberg T, Jäncke L (2002) Calibrated LCD/ TFT stimulus presentation for visual psychophysics in fMRI. J Neurosci Methods 121:103-110

55. Sunness JS, Massof RW, Johnson MA, Finkelstein D, Fine SL (1985) Peripheral retinal function in age-related macular degeneration. Arch Ophthalmol 103:811-816

56. Thorn F, Thorn S (1989) Speechreading with reduced vision: a problem of aging. J Opt Soc Am A 6(4):491-499

57. Tikellis G, Robman LD, Harper A, McNeil JJ, Taylor HR, McCarty CA (2000) Methods for detecting age-related maculopathy: a comparison between photographic and clinical assessment. Clin Experiment Ophthalmol 28:367-372

58. Treutwein B (1995) Adaptive psychophysical procedures. Vis Res 35:2503-2522

59. Treutwein B (1997) YAAP: yet another adaptive procedure. Spat Vis 11:129-134

60. Treutwein B, Rentschler I (1992) Double-pulse resolution in the visual field: The influence of temporal stimulus characteristics. Clin Vis Sci 7:421-434

61. Tyler CW (1989) Two processes control variations in flicker sensitivity over the live span. J Opt Soc Am A 6:481-490

62. Vingerling JR, Dielemans I, Hofman A, Grobbee DE, Hijmering M, Kramer CF, de Jong PT (1995) The prevalence of agerelated maculopathy in the Rotterdam study. Ophthalmology 102:205-210

63. Watson AB (1980) Summation and discrimination of gratings moving in opposite directions. Vis Res 20:341-347 